\title{
Sleeping Pattern of Medical Students Preceding Viva Examination and Their Performance
}

\author{
Mukhtar Ansari ${ }^{1}$ \\ 'Department of Clinical Pharmacy, College of Pharmacy, University of Hail, Saudi Arabia.
}

\section{ABSTRACT}

Introduction: Sleep is an important determinant of keeping healthy physically and mentally. Deviation in sleep is a common problem among students during examinations. The purpose of this study is to determine students' sleep pattern during night preceding viva examination and its correlation with performance.

Methods: This was a cross-sectional prospective study conducted between January and February 2014 among $1^{\text {st }}$ and $2^{\text {nd }}$ year MBBS students of National Medical College, Birgunj, Nepal who appeared in University's final practical examinations. Based on simple random sampling approach, each of the 280 participants was allowed to pick out five pieces of lottery papers and they were asked the five questions resembling the number in the list of questions.

Results: Among the total 280 students, $74.6 \%$ were from India and $25.4 \%$ were from Nepal, and majorities $(63 \%)$ of them were males. Fifty two percent of the students either could not sleep at all or slept just for 1 to 1.5 hours while $12 \%$ slept for 5 to 6.5 hours. Two-third (66\%) of the students was able enough to achieve one to two scores, and only $1.8 \%$ could succeed to get the maximum score of five. The correlation between hours of sleep preceding examination and the score achieved was positively $(\mathrm{r}=0.701)$ and statistically significantly correlated $(\mathrm{p}<0.001)$.

Conclusions: There is a trend among the medical students either not to sleep or sleep only for few hours preceding viva examination that result in poor performance in examinations.

Keywords: medical; Nepal; performance; sleep deprivation; students.

\section{INTRODUCTION}

Sleep is an important determinant of keeping healthy physically and mentally. Duration, quality and timing of sleep are the critical issues directly linked with the performance. ${ }^{1,2}$

About $82-90 \%$ of the students sleep less during examination days due to fear of examinations..$^{3,4}$ Furthermore, first year medical students face more academic stress due to newer environment of medical education. ${ }^{5}$ Though examination in any form is a method of evaluating the students, theoretical paper examination and viva examinations are different. In theory examinations, questions are of different types and students have choice for solving easy questions

Correspondence: Dr. Mukhtar Ansari, Assistant Professor \& Coordinator of Research, Department of Clinical Pharmacy, College of Pharmacy, University of Hail, Saudi Arabia. E-mail: mukhtaransari@ hotmail.com, Phone: +966578115136 . 
first and think for answers. ${ }^{6}$ But, the scenario is just opposite in viva examinations. Additionally, examiner may ask a simple question in a difficult way or many questions from a single topic based on questions arising from the answers and so forth. ${ }^{7-9}$

Thus, the author devised this study to determine students' sleep pattern during night preceding viva examination and its correlation with performance.

\section{METHODS}

This was a cross-sectional prospective study conducted among $1^{\text {st }}$ and $2^{\text {nd }}$ year MBBS students of National Medical College (NMC), Birgunj, Nepal who appeared in Tribhuvan University's final practical examinations. The study was carried out between January and February 2014.

National Medical College is a 1050 bedded private medical school located in central Terai (plain) region of Nepal adjoining Indian border. The target was to enroll all of the 290 students however only 280 students were included based on inclusion criteria of the study. Two sets of questions related to clinical pharmacology from the syllabus of first and second year MBBS curriculum of Tribhuvan University were prepared. Each of the two sets contained 50 carefully selected lists of questions from the syllabus of $1^{\text {st }}$ year and $2^{\text {nd }}$ year MBBS courses.

All of the students were kept in a big hall and based on their roll numbers, one student at a time was called for the interview. Number one to 50 were written in small uniform sized square piece of papers, folded and kept in a vessel. Each of the students was asked to pick randomly five pieces of the lottery paper from the vessel and they were asked the five questions from the list according to the lottery numbers. One score was allocated for each correct response. Out of a maximum of five scores allocated for five questions, scores obtained by the students based on their performance in VIVA were noted. After the interview was over, the interviewed student was not allowed to meet the remaining students to avoid sharing of the questions asked. Informed consent was taken from all of the participants and the students agreed to participate in the study were only enrolled. This study was approved by the Institution Review Board (IRB) of the National Medical College.

Regarding the data on sleep habit, every student was asked about the time they slept in preceding night and woke up and the hours of sleep was calculated. Due to annual final examination system, students have to tackle with larger contents of the subjects. On the other hand, unlike theory examinations, viva or practical examinations are conducted every day without any gap and students have to appear in viva examination of different subjects each day. As a result, students hardly get time to sleep in daytime or even at night during practical examinations. Therefore, the students who did not sleep at daytime were only included in the study. Similarly, students with a habit of drinking alcohol and smoking were excluded from the study. But, the students who consumed either coffee or tea were included because it is quite common among the students to have coffee or tea during examination days.

Data were entered in IBM SPSS Statistics 21 and analyzed for descriptive and inferential statistics. The results were expressed as counts and percentages. Associations were tested using the chi-square test. Pearson correlation test was used to see the correlation between the students' hours of sleep preceding viva examination and the scores achieved. A priori $p$ value $<0.05$ was considered statistically significant throughout the analyses.

\section{RESULTS}

Among the total 280 students, 176 (63\%) were males followed by female 104 (37\%). The nationality or origin of the students shows that about three-fourth (74.6\%) of the students were from India and the remaining onefourth $(25.4 \%)$ were from Nepal. About $48 \%$ of the students were from $1^{\text {st }}$ year and the remaining $52 \%$ students were from $2^{\text {nd }}$ year of MBBS program. Median score and (IQR) achieved by the students was 2 (1-3).

Table 1 illustrates the pattern of hours of sleep preceding the examination. More than one half $(52 \%)$ of the students either could not sleep at all or slept just for 1 to 1.5 hours. On the other hand, less than $12 \%$ slept for a significant number of hours, i.e. 5 to 6.5 hours.

\begin{tabular}{|c|c|c|}
\hline $\begin{array}{l}\text { Hours slept preceding } \\
\text { exam }\end{array}$ & Number & Percentage \\
\hline 0 hour & 47 & 16.8 \\
\hline 1 to 1.5 hours & 99 & 35.3 \\
\hline 2 to 2.5 hours & 49 & 17.5 \\
\hline 3 to 3.5 hours & 19 & 6.8 \\
\hline 4 to 4.5 hours & 33 & 11.8 \\
\hline 5 to 5.5 hours & 23 & 8.2 \\
\hline 6 to 6.5 hours & 10 & 3.6 \\
\hline
\end{tabular}

About two third $(66 \%)$ of the students were able enough to achieve one to two scores out of a total of five scores whereas, only less than two percentage of the students could succeed to get the maximum or highest score (Table 2). Though passing examinations 
and having grip on contents of subject matter are interrelated, they are not always true. In this study, we categorized the students in four classes based on the scores they gained in viva examinations. The students who secured 1 to 2 scores were labelled as 'below average'. Similarly, 3 scores (average), 4 scores (above average) and 5 scores (outstanding).

\begin{tabular}{|ccc|}
\hline $\begin{array}{l}\text { Table 2. Pattern of scores gained in viva examination } \\
\text { (out of five scores). }\end{array}$ & Number & Percentage \\
\hline $\begin{array}{c}\text { Score/marks } \\
\text { achieved }\end{array}$ & 125 & 44.6 \\
1 score & 60 & 21.4 \\
2 score & 58 & 20.7 \\
3 score & 32 & 11.4 \\
4 score & 5 & 1.8 \\
\hline
\end{tabular}

Chi-square test was used to see the difference in scores gained between male and female and it was statistically insignificant $(p=0.143)$. The correlation between hours of sleep preceding viva examination and the score achieved was positively $(r=0.701)$ and statistically significantly $(p<0.001)$ correlated. There were no statistically significant differences in association between the year (first and second year) students and gender $(p=0.464)$ and age $(p=0.087)$. Additionally, the association between nationality of the students and the score gained was also insignificant $(p=0.128)$.

\section{DISCUSSION}

Medical education is a highly sensible and difficult field and it has direct practical implication on human life. Therefore, this profession is considered as the most respectful in the society. In medical education, there are various subjects and students have to study them in integrated manner as they have to appear in exam in integrated manner. This impose more stress on medical students and thus it becomes hard for them to pass in examinations. ${ }^{10,11}$

Students studying at National Medical College, Birgunj, Nepal were from Nepal and India with more than $74 \%$ from India. Indian students wish to be enrolled in Nepalese medical colleges preferably the colleges situated in cities located in Indo-Nepal boarder. The reasons behind this are lower cost of medical education in Nepal, easy process of getting admission being foreigner and easy access as there is no requirement of visa for Indians to visit, stay and study in Nepal. ${ }^{12,13}$

About $63 \%$ of the students who participated in the study were male. This clearly indicates the parents' preference on sons compared to daughters for medical education in this region. ${ }^{14}$ But, the study conducted by
Rizwi et al in Pakistan found an opposite trend in which about $78 \%$ of the medical students were females. ${ }^{15}$ There can be various factor for gender preference for medical education however motivation of girls towards medical education is increasing in recent time. ${ }^{16}$

Fifty two percent of the students were from $2^{\text {nd }}$ year of the MBBS course and majority of them were from India compared with the $1^{\text {st }}$ year students. In fact, students from India were getting admission in Nepalese medical schools just because of personal interview and without appearing in entrance examination. However, recently government of Nepal realized the importance of conducting entrance examination for Indian students too like Nepalese students and so the numbers of students from India get declining from last two to three years. Thus, the numbers of students were comparatively less in $1^{\text {st }}$ year.

Sleeping less number of hours during examinations compared with usual days is quite common however; it is surprising to know that more than one half $(52 \%)$ of the students either could not sleep at all or slept just for 1 to 1.5 hours in preceding night of examinations. This is due to intensified fear of viva examinations among the medical students. ${ }^{17}$ The pattern of sleep and study in usual days is very irregular among the students. ${ }^{18}$ Another important component is the timing of sleep. It is quite usual among the medical students to have altered timing of sleep during examination days. ${ }^{19}$ This further causes more stress on students and ultimately leads to failure in examinations. ${ }^{20,21}$

Gender does not have any significant differences on hours of sleep and score gained. Likewise, there were no significant differences between the year (first and second year) students and gender, and age. The association between nationality of the students and the score gained was also insignificant. However, there was strongly positive correlation between hours of sleep preceding examination and the score achieved in viva. Thus, proper and sufficient hours of sleep preceding examination are vital to score good in viva examinations.

There was no structured questionnaire for data collection in this study. There is chances of individual variation, question types during the viva examination which cannot be taken into consideration.

\section{CONCLUSIONS}

There is a trend among the medical students either not to sleep or sleep only for few hours preceding viva examinations. Furthermore, students who did not sleep properly in preceding night could not be able to respond well in viva and ultimately their performance is poor. 


\section{ACKNOWLEDGEMENT}

The author would like to thank students and faculty members of pharmacology department, National
Medical College for cooperation.

\section{REFERENCES}

1. National, Heart, Lung and Blood Institute. why is sleep important?[Online]. 2012 [Cited 2016 Jan 4]; Available from: http://www.nhlbi.nih.gov/health/health-topics/topics/ sdd/why.html

2. Fatima K, Rizvi F, Ali M, Afzal M. Sleep Pattern and Sleep Duration of Medical College Students. Annals of Pakistan Institute of Medical Sciences. 2011;7(2):79-81.

3. Al Ghamdi AA. Sleep Deprivation and Academic Performance of Students in the Collage of Nursing at King Saud University. World Applied Sciences Journal. 2013;27(2):155-67.

4. Kazim M, Abrar A. Sleep Patterns and Association with Academic Performance in Students of a Medical College in Pakistan. Khyber Medical University Journal. 2011;3(2):57-60.

5. Nakalema G, Ssenyonga J. Academic stress: Its causes and results at a Ugandan University. African Journal of Teacher Education. 2013;3(3):1-21.

6. Patel BS, Kubavat A, Piparva K. Correlation of students performance in theory and practical of final summative pharmacology examination in MBBS curriculum: A critical insight. National Journal of Physiology, Pharmacy and Pharmacology. 2013;3(2):171-75.

7. Pearce G. Viva voce (Oral Examination) as an assessment method. Journal of Marketing Education. 2009;31(2):120-30.

8. Joughin G. A short guide to oral assessment [Online]. [Cited 2016 Jan 4]; Available from: https://www.leedsbeckett. ac.uk/publications/files/100317_36668_ShortGuideOralAssess1_WEB.pdf

9. Haque M, Yousuf R, Abu Bakar SM, Salam A. Assessment in undergraduate medical education: Bangladesh perspectives. Bangladesh Journal of Medical Science. 2013;12(4):353-63.

10. Iqbal S, Gupta S, Venkatarao E. stress, anxiety \& depression among medical undergraduate students \& their socio-demographic correlates. Indian J Med Res. 2015;141(3):354-57.

11. Salgar ST. Stress in first year medical students. International Journal of Biomedical And Advance Research. 2014;5(1):5-6.
12. Higher Education Review. Expensive medical education compelling students to study abroad [Online] 2013[Cited 2016 Jan 4]; Available from: http://www.theher.in/ magazine/expensive-medical-education-compellingstudents-to-study-abroad-ZBNZ330192207.html

13. Sustainable Education and Economic Developent. MBBS in Nepal for Indian students [Online]. [Cited 2015 Nov 7]; Available from: http://www.seedmbbs.com/mbbs/nepal. html

14. Dixit H, Maharjan S. Review of Admission of MBBS Students at KMC. Kathmandu Univ Med J. 2003;1(3):212-21.

15. Rizvi AH, Awaiz M, Ghanghro Z, Jafferi MA, Aziz S. Pre-examination's stress in second year medical students in a government college. J Ayub Med Coll Abbottabad. 2010;22(2):152-55

16. Shankar P, Singh K, Singh S. Possible impact of increase in female medical student admissions in Nepal: Findings from a qualitative study among medical undergraduates. Australas Med J. 2012;5(3): 184-93.

17. Pahwa B, Goyal S, Srivastava K, Saldanha D, Bhattacharya D. A study of exam related anxiety amongst medical students. Industrial Psychiatry Journal. 2008;17(1): 46-48.

18. BaHammam AS, Alaseem AM, Alzakri AA, Almeneessier AS, Sharif MM. The relationship between sleep and wake habits and academic performance in medical students: a cross-sectional study. BMC Med Educ. 2012; 12(61).

19. Genzel L, Ahrberg K, Roselli C, Niedermaier S, Steiger A, Dresler $\mathrm{M}$, et al. Sleep timing is more important than sleep length or quality for medical school performance. Chronobiol Int. 2013;30(6):766-71.

20. Ahrberg K, Dresler M, Niedermaier S, Steiger A, Genzel L. The interaction between sleep quality and academic performance. J Psychiatr Res. 2012;46(12):1618-22.

21. Chimanlal PH, Jayshree B. Stress levels and "immediate examination performance" of medical students. International Archives of Integrated Medicine. 2015;2(5):30-36. 